\title{
Wessex cardiac surgery follow-up survey: the quality of life after operation
}

\author{
J. K. ROSS, A. E. DIWELl, J. MARSH, J. L. MONRO, AND D. J. P. BARKER ${ }^{1}$ \\ From Wessex Cardio-Thoracic Centre, Western Hospital, Southampton and Community Medicine, \\ South Block, General Hospital ${ }^{1}$, Southampton, Hants, UK
}

Ross, J. K., Diwell, A. E., Marsh, J., Monro, J. L., and Barker, D. J. P. (1978). Thorax, 33, 3-9. Wessex cardiac surgery follow-up survey: the quality of life after operation. Two hundred consecutive adult patients in all diagnostic categories who had undergone open-heart surgery at the Wessex Regional Cardio-Thoracic Centre were assessed for the subsequent 20 months. They were interviewed, using a standard questionnaire, at the time of referral for surgery and at 2,8 , and 20 months after operation. The questionnaire elicited information on physical activity, employment, dependence on others, leisure activities, mood, and sexual relationships. Patients under 21 were excluded, but there was no upper age limit. Sixty-six per cent were over the age of 50, and many who were close to or over retirement age were included.

The results show that 20 months after operation $68 \%$ of the survivors denied limitation of normal activity compared with a preoperative figure of $12 \%$, and that there had been a corresponding pattern in return to useful employment. Seventy-four per cent of men of employable age were back at work or capable of gainful employment, and $76 \%$ of these had returned to their usual jobs. No correlation was found between the time taken to resume work and the patient's age or diagnosis. There was an equally satisfactory trend in female employment in both full- and part-time jobs, amounting to a $16 \%$ increase on the preoperative figure.

Decreased dependence upon others was readily identified as a significant gain for $73 \%$ of patients at the eight-month follow-up. Throughout the subsequent year the favourable trends in employment statistics, use of leisure time, mood, and sexual relationships point to an overall improvement in the quality of life for the majority of patients.

During the past two decades cardiac surgery has developed rapidly, and much interest has been directed towards the technical challenge on one hand and to crude survival statistics on the other.

Now that the specialty has passed from the development phase to one of consolidation and wide acceptance, there is a need to find out more about the quality of life of patients who have undergone open-heart procedures and to learn more of the value of this type of surgery in terms of return to useful employment, use of leisure time, and dependence upon other people. By producing evidence on these and other aspects of life after open-heart surgery a background of fact can be established against which the total effort involved may be fairly judged.

Without such facts the usefulness of the surgical procedure to the individual, his family, and the community cannot be properly assessed; nor can accurate comparisons be made when 'priorities' for the treatment of disabling and lifethreatening disease have to be established.

The survey reported here was designed to provide information about the changes in patients' activities, occupation, and way of life before and at set intervals after open-heart surgery. In this way we set out to determine more exactly than is possible by conventional clinical follow-up what is being derived from the effort of a regional cardiac surgical service.

This paper presents data gathered over a period of three years from a series of interviews with a group of 200 consecutive adult patients.

\section{Method}

The Wessex Cardio-Thoracic Unit carries out about 350 open-heart procedures annually (Ross et al., 1976). As a regional unit serving a geo- 
graphically defined area with a population of 2.7 million in the counties of Hampshire, Dorset, Wiltshire, and the Isle of Wight, it provides the opportunity to study a representative group of patients who have been subjected to open-heart surgery.

Starting in June 1973, patients' names were taken as they appeared on the waiting list for surgery. Patients under the age of 21 were excluded, but in selection for the study no account was taken of the diagnosis. The required number of 200 adult patients was obtained by July 1974.

The patients were asked for their cooperation in the survey, and both the general practitioner and the referring consultant were informed of their patient's inclusion. At the outset the patients were told that the interviewers (JM and AD) would have no influence on their treatment.

Each patient was interviewed, using identical questionnaires, at four preset intervals. The first interview took place after referral for surgery and was conducted in the patient's own home, unless he or she was admitted as an emergency. Whenever possible the other members of the family were present. The postoperative interviews were timed to coincide with routine out-patient appointments at 2, 8, and 20 months after leaving hospital. Again, whenever possible, relatives accompanying the patient were present at the interview.

All postoperative interviews were held in the interviewer's office, situated at a distance from the out-patient department and thereby divorced from the clinical atmosphere of the consulting room. It was hoped that this would reduce bias caused by a patient's tendency to exaggerate his progress as a means of expressing appreciation to the surgeon and his team. Every three months throughout the survey an independent interviewer carried out duplicate interviews on a sample of patients to ensure that the results being obtained were reproducible.

\section{Results}

The group of 200 patients comprised 100 men and 100 women. The age range for men was 21-74 years with a mean of 53, and for women, 23-71 years with a mean of 52 (Table 1). Eighty-one per cent were married and they had on average two children.

The interval between the disorder first being diagnosed and referral for surgery differs between the sexes, women having considerably longer histories of cardiac disease than men (Table 2). For example, $59 \%$ of women as opposed to $22 \%$
Table 1 Age when referred for open-heart surgery

\begin{tabular}{llllllll}
\hline \multicolumn{7}{c}{ Age $(y r)$} \\
\cline { 2 - 8 } & $21-29$ & $30-39$ & $40-49$ & $50-59$ & $60-69$ & $70+$ & Total \\
\hline Males & 4 & 11 & 19 & 35 & 28 & 3 & 100 \\
Females & 5 & 9 & 19 & 42 & 23 & 2 & 100 \\
Total & 9 & 20 & 38 & 77 & 51 & 5 & 200 \\
\hline
\end{tabular}

Table 2 Interval between first diagnosis and referral for operation

\begin{tabular}{lrllllllll}
\hline & \multicolumn{1}{l}{ Years } & & & & & \\
\cline { 2 - 8 } & $<1$ & $1-4$ & $5-9$ & $10-14$ & $15-19$ & $20-24$ & $25+$ & Total \\
\hline Males & 24 & 32 & 13 & 9 & 4 & 3 & 15 & 100 \\
Females & 8 & 11 & 10 & 12 & 5 & 7 & 47 & 100 \\
Total & 32 & 43 & 23 & 21 & 9 & 10 & 62 & 200 \\
\hline
\end{tabular}

of men were diagnosed more than 15 years before referral.

This sex difference is still apparent, although less striking, when the interval between the onset of serious deterioration and referral for surgery was measured. Fifty-five per cent of men were referred for surgery within nine months of the onset of marked cardiac deterioration, whereas the equivalent figure for women was $35 \%$ (Table 3).

Table 3 Interval between onset of cardiac deterioration and surgical referral

\begin{tabular}{lllllllll}
\hline & \multicolumn{2}{l}{ Months } \\
\cline { 2 - 8 } & $<1$ & $1-4$ & $5-9$ & $10-14$ & $15-19$ & $20-24$ & $25+$ & Total \\
\hline Males & 2 & 24 & 29 & 20 & 3 & 11 & 11 & 100 \\
Females & 2 & 17 & 16 & 15 & 8 & 21 & 21 & 100 \\
Total & 4 & 41 & 45 & 35 & 11 & 32 & 32 & 200 \\
\hline
\end{tabular}

The operations (Table 4) comprised 109 (55\%) single valve replacements with an overall mortality of 16 (including both hospital and late deaths to the time limit of the survey). There were $45(23 \%)$ multiple valve replacements with 13 deaths: 18 $(9 \%)$ patients were operated on for congenital heart disease with one death: $14(7 \%)$ patients required coronary artery bypass grafts. There were nine $(4 \%)$ miscellaneous operations with one death. Five patients $(2 \%)$ did not undergo surgery, three because they died before an operation could be performed and two because they refused operation.

Omitting the deaths and refusals of surgery from the long-term analysis, there remained 164 patients ( 80 men and 84 women) whose progress can be traced from the preoperative period to a point 20 months after open-heart surgery. 
Table 4 Number of survivors and deaths during survey period, according to type of operation

\begin{tabular}{|c|c|c|c|c|c|c|c|}
\hline \multirow[b]{2}{*}{ Operation } & \multicolumn{3}{|c|}{ Survived } & \multicolumn{3}{|c|}{ Died } & \multirow[b]{2}{*}{ Total } \\
\hline & $M$ & $F$ & $T$ & $\boldsymbol{M}$ & $\boldsymbol{F}$ & $T$ & \\
\hline \multirow{2}{*}{$\begin{array}{l}\text { Aortic valve replacement } \\
\text { (AVR) } \\
\text { Mitral valve replacement } \\
\text { (MVR) }\end{array}$} & 31 & 13 & 44 & 6 & 1 & 7 & 51 \\
\hline & 17 & 31 & 48 & 4 & 5 & 9 & 57 \\
\hline \multirow{6}{*}{$\begin{array}{l}\text { Tricuspid valve } \\
\text { replacement (TVR) } \\
\text { AVR and MVR } \\
\text { MVR and TVR } \\
\text { AVR, MVR, and TVR } \\
\text { Atrial septal defect (ASD) } \\
\text { Ventricular septal } \\
\text { defect (VSD) }\end{array}$} & $\mathbf{0}$ & 1 & 1 & & 0 & $\mathbf{0}$ & \\
\hline & 11 & 12 & 23 & 4 & 7 & 11 & 34 \\
\hline & 1 & 2 & 3 & 1 & 0 & 1 & 4 \\
\hline & 0 & 6 & 6 & 0 & 1 & 1 & 7 \\
\hline & 4 & 11 & 15 & 0 & 1 & 1 & 16 \\
\hline & 1 & 1 & 2 & 0 & 0 & $\mathbf{0}$ & 2 \\
\hline $\begin{array}{l}\text { Coronary artery bypass } \\
\text { graft (CABG) }\end{array}$ & 13 & 1 & 14 & 0 & 0 & 0 & 14 \\
\hline Miscellaneous & 4 & 4 & 8 & 1 & 0 & 1 & 9 \\
\hline Total & & & 164 & & & 31 & 195 \\
\hline Refusal of surgery & 1 & 1 & 2 & & & & \\
\hline Preoperative death & & & & 3 & $\mathbf{0}$ & 3 & 3 \\
\hline Total & & & 166 & & & 34 & 200 \\
\hline
\end{tabular}

$\mathbf{M}=$ male; $\mathbf{F}=$ female; $\mathbf{T}=$ total.

PHYSICAL SYMPTOMS AND EXTENT OF ACTIVITY

The preoperative level of disability was assessed by both cardiologist and surgeon and expressed according to the New York Heart Association classification (Harris, 1970). Using this method, 89 $(54 \%)$ of the 164 patients fell into categories 3 and 4 , indicating that for more than half of the patients symptoms were apparent on minimal exertion or at rest (Table 5).

Table 5 Preoperative disability grade (New York Heart Association)

\begin{tabular}{lllllll}
\hline & \multicolumn{2}{l}{ Grade } & & & & \\
\cline { 2 - 7 } & Not disabled & 1 & 2 & 3 & 4 & Total \\
\hline Males & 3 & 4 & 28 & 35 & 10 & 80 \\
Females & 2 & 10 & 28 & 41 & 3 & 84 \\
Total & 5 & 14 & 56 & 76 & 13 & 164 \\
\hline
\end{tabular}

Dyspnoea was measured on the World Health Organization scale (Rose and Blackburn, 1968). Table 6 shows that all but $23(14 \%)$ patients complained of shortness of breath before operation, $80(49 \%)$ falling into categories 3 and 4 .

Table 6 Severity of dyspnoea (WHO classification)

\begin{tabular}{lccc}
\hline & \multicolumn{2}{c}{ Months after operation } \\
\cline { 3 - 4 } Grade & Before operation & \multicolumn{1}{c}{8} & 20 \\
\hline None & 23 & 100 & 102 \\
1 & 12 & 32 & 28 \\
2 & 49 & 26 & 27 \\
3 & 26 & 2 & 2 \\
4 & 54 & 4 & 5 \\
Total & 164 & 164 & 164 \\
\hline
\end{tabular}

Eight months after surgery $100(61 \%)$ patients experienced total relief from dyspnoea, the figure rising to $102(62 \%)$ by the 20 -month stage.

If a patient felt before operation that his normal activities were limited, he was asked to name the main factor responsible. The usuat reasons given were dyspnoea, chest pain, fatigue, or fear of exertion. Table 7 shows an improvement after operation in all but fear of exertion'. No limitation of normal activity was found in 19 patients $(12 \%)$ before operation; by 20 months after surgery this figure had risen to $111(68 \%)$.

Table 7 Reasons for limited activity pre- and post-operatively

\begin{tabular}{lccc}
\hline & & \multicolumn{2}{c}{ Months after operation } \\
\cline { 3 - 4 } Reason & Before operation & 8 & 20 \\
\hline No limit & 19 & 85 & 111 \\
Dyspnoea & 75 & 21 & 12 \\
Chest pain & 22 & 5 & 6 \\
Fatigue & 30 & 18 & 19 \\
Fear of exertion & 3 & 18 & 3 \\
Miscellaneous & 15 & 17 & 13 \\
Total & 164 & 164 & 164 \\
\hline
\end{tabular}

MALE EMPLOYMENT

The figure shows that immediately before hospital admission for open-heart surgery $11(14 \%)$ of the 80 male patients had retired, two of them before the statutory age. Of the remaining and potentially employable 69 men, 36 were on sick leave due to disability from heart disease and had been so for an average of 22.5 weeks. A further 10 were registered as unemployed and were therefore, by definition, considered capable of work although out of a job. The remaining 23 were working until admission to hospital.

After operation, and an average of 14.5 weeks' sick leave after leaving hospital, $46(57 \%)$ of the 80 men were back at work by the eight-month interview. Twenty months after surgery $50(63 \%)$ were in regular full-time employment, 31 of these having returned to work within the first four months. Four $(5 \%)$ were still off sick; nine $(11 \%)$ remained unemployed; and $17(21 \%)$ had retired.

Of the 50 men at work 20 months after surgery, 38 had resumed their usual employment. A further five had obtained less demanding jobs than before, and two others were on government retraining schemes. The remaining five were unable to convince their employers that they were capable of doing their usual work and had changed jobs. Twenty of the 38 men who had resumed their former employment were known to have physically demanding jobs classified as skilled manual, 

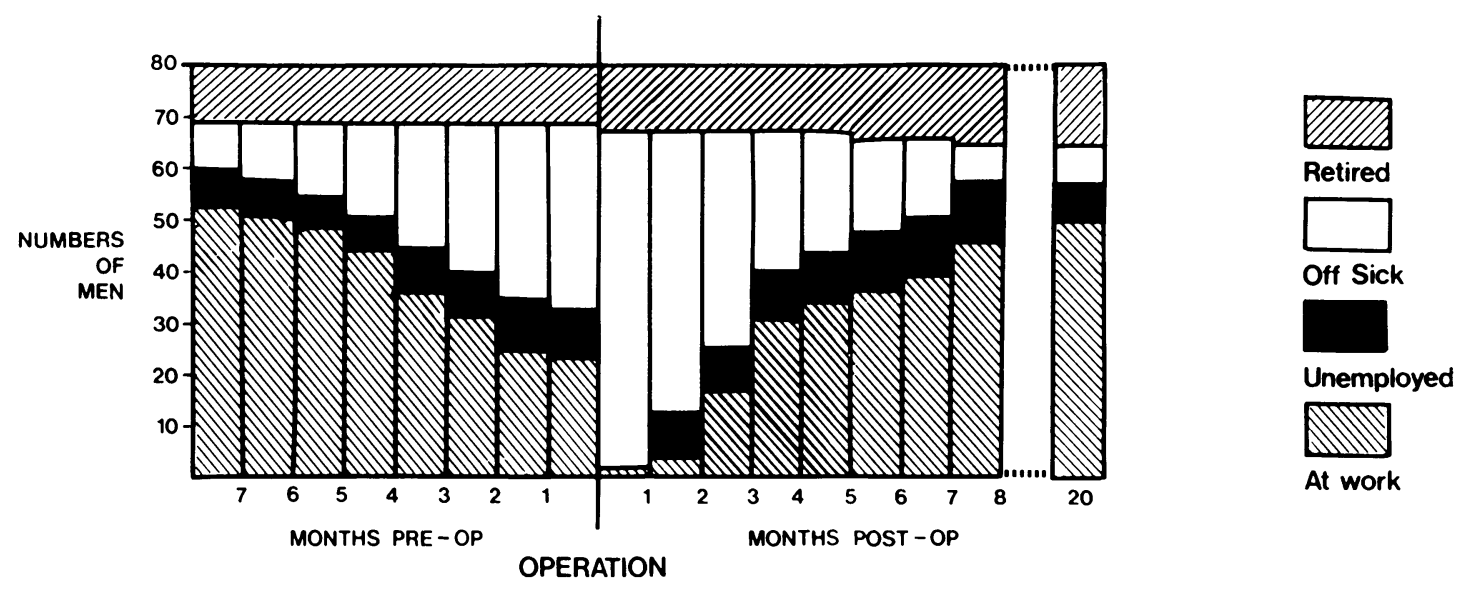

At work

Figure Employment status of men before and up to 20 months after operation.

Table 8 Social class for 38 men who had resumed their usual jobs by 20 months after operation

\begin{tabular}{llllllll}
\hline & $\begin{array}{l}\text { Professional } \\
\end{array}$ & $\begin{array}{l}\text { Intermediate } \\
I I\end{array}$ & $\begin{array}{l}\text { Skilled }(N M) \\
I I I(N M)\end{array}$ & $\begin{array}{l}\text { Skilled }(M) \\
I I I(M)\end{array}$ & $\begin{array}{l}\text { Part skilled } \\
\text { IV }\end{array}$ & $\begin{array}{l}\text { Unskilled } \\
\text { V }\end{array}$ & $\begin{array}{l}\text { Total } \\
\text { No. of men }\end{array}$ \\
\hline
\end{tabular}

partly skilled manual, or unskilled (Office of Population Censuses and Surveys, 1970) (Table 8).

There was no apparent correlation between age and the duration of sick leave (Table 9), and, although the numbers are small, the nature of the cardiac lesion seemed unrelated to the duration of sick leave (Table 10).

Table 9 Duration of postoperative sick leave, by age of patient

\begin{tabular}{lllllll}
\hline \multicolumn{7}{c}{ Postoperative sick leave (weeks) } \\
\cline { 2 - 6 } Age $(y r)$ & $0-3$ & $4-7$ & $8-11$ & $12-15$ & 16 and over & Total \\
\hline $21-29$ & 0 & 0 & 1 & 1 & 0 & 2 \\
$30-39$ & 0 & 0 & 3 & 4 & 3 & 10 \\
$40-49$ & 0 & 1 & 3 & 4 & 5 & 13 \\
$50-59$ & 0 & 1 & 5 & 3 & 7 & 16 \\
$60-69$ & 1 & 1 & 1 & 2 & 4 & 9 \\
Total & 1 & 3 & 13 & 14 & 19 & 50 \\
\hline
\end{tabular}

Table 10 Duration of postoperative sick leave, by type of operation

\begin{tabular}{|c|c|c|c|c|c|c|}
\hline \multirow[b]{2}{*}{ Operation } & \multicolumn{5}{|c|}{ Postoperative sick leave (weeks) } & \multirow[b]{2}{*}{ Total } \\
\hline & $0-3$ & $4-7$ & $8-11$ & $12-15$ & $\begin{array}{l}16 \text { and } \\
\text { over }\end{array}$ & \\
\hline Aortic valve replacement & 1 & 1 & 6 & 3 & 6 & 17 \\
\hline Mitral valve replacement & 0 & 0 & 1 & 3 & 6 & 10 \\
\hline Multiple valve replacement & 0 & 1 & 3 & 4 & 2 & 10 \\
\hline Coronary artery graft & $\mathbf{0}$ & 1 & 1 & 2 & 4 & 8 \\
\hline Atrial septal defect & 0 & 0 & 1 & 2 & 1 & 4 \\
\hline Miscellaneous & 0 & 0 & 1 & $\mathbf{0}$ & 0 & 1 \\
\hline Total & 1 & 3 & 13 & 14 & 19 & 50 \\
\hline
\end{tabular}

FEMALE EMPLOYMENT

Before operation $70(83 \%)$ of the 84 women were classified as 'housewives'. Of the remainder, 11 $(13 \%)$ had part-time and three $(4 \%)$ full-time jobs.

Eight months after operation (Table 11), the number of 'housewives' had decreased to 57 $(68 \%)$ : part-time employees rose to 20 and fulltime to seven. During the year that followed, seven women gave up their gainful employment; in only two cases was this related to cardiac disease. Eight other women found work during this time so that there was an overall rise in the total number of women employed 20 months after surgery. Sixteen $(19 \%)$ are now engaged in parttime and 12 in full-time work. Fifty-six $(67 \%)$ remain classified as 'housewives'.

In assessing the capability of the 56 housewives they were asked whether they could manage the housework and shopping alone. Before operation $43(77 \%)$ required help with the housework and

Table 11 Female employment before and after operation

\begin{tabular}{llll}
\hline & & \multicolumn{2}{l}{ Months after operation } \\
\cline { 3 - 4 } Type of work & Before operation & 8 & 20 \\
\hline Housework & 70 & 57 & 56 \\
Full-time & 3 & 7 & 12 \\
Part-time & 11 & 20 & 16 \\
Total & 84 & 84 & 84 \\
\end{tabular}


$49(88 \%)$ required help with the shopping (Table 12). Twenty months after operation only $17(30 \%)$ needed assistance with housework and $24(43 \%)$ with the shopping. Where aid was needed in the home, only five women made use of the home help service or engaged private help. The main source of support came from the spouse and immediate family, both before and after surgery.

Table 12 Limitation of performance of household duties among 56 housewives

\begin{tabular}{llll}
\hline & & \multicolumn{2}{c}{ Months after operation } \\
\cline { 3 - 4 } Assistance needed & Before operation & 8 & 20 \\
\hline With housework & 43 & 23 & 17 \\
With shopping & 49 & 32 & 24 \\
\hline
\end{tabular}

\section{FAMILY LIFE}

Before surgery 57 of the 164 patients had impairment of one or more basic activity (Table 13). Five $(3 \%)$ were bedridden, five $(3 \%)$ required help to walk, $18(11 \%)$ could not manage the stairs alone, and $50(31 \%)$ could not leave the house unaccompanied. After operation there was a progressive improvement so that after 20 months only 13 had one or more impairment of activity.

Table 13 Impairment of activity among the 164 patients

\begin{tabular}{llll}
\hline & & \multicolumn{2}{l}{$\begin{array}{l}\text { Months after } \\
\text { operation }\end{array}$} \\
\cline { 2 - 5 } Impairment & $\begin{array}{l}\text { Before } \\
\text { operation }\end{array}$ & 8 & 20 \\
\hline Bedridden & 5 & 0 & 0 \\
Assistance needed with walking & 5 & 2 & 6 \\
Assistance needed with stairs & 18 & 5 & 6 \\
Assistance needed with leaving the house & 50 & 6 & 4 \\
\hline
\end{tabular}

Before operation $95(58 \%)$ said that their physical dependence on other members of the family had increased as their cardiac state deteriorated. At eight months after operation patients were asked if their dependency had changed since their immediate postoperative state. One hundred and twenty $(73 \%)$ said that it had lessened. At 20 months after operation 37 of these 120 patients felt less dependent than at eight months, five felt more dependent, and 78 felt unchanged.

\section{HOBBIES AND LEISURE}

Before operation 127 patients had reduced the time spent on one or more of their leisure activities. Eight months after operation 111 patients had increased the amount of time spent on hobbies. This renewal of leisure activity continued to the 20-month stage, with a marked increase in the more active type of pursuit.

\section{SEXUAL RELATIONSHIPS}

To what extent sexual relationships had been affected by the patient's ill-health was a question put to the 136 married patients at the first interview. Eighty-five $(63 \%)$ said there had been a deterioration while the remaining $51(37 \%)$ had experienced no change.

Postoperative improvement in this respect was slow due, in many cases, to a fear of exertion and lack of confidence. Another reason given for this slow progress was the unfamiliar sound of a prosthetic valve. By 20 months after surgery 42 $(31 \%)$ said that sexual relationships had improved since operation.

\section{MOOD}

Before operation $101(62 \%)$ patients had felt some deterioration of mood while $55(34 \%)$ recorded no change. The postoperative improvement shown by $92(56 \%)$ patients was usually initiated by a return to work or the resumption of previous activities.

\section{Discussion}

This survey was carried out to obtain information on a relatively neglected aspect of open-heart surgery, namely, the pre- and post-operative quality of life for the patient and the family. Although there have been studies of patients' activities after myocardial infarction (Cay et al., $1972,1973)$, the results of cardiac surgery have not received similar attention.

A regional cardiac surgical unit serving a defined population gives the opportunity of conducting a follow-up study in a group of patients who represent a reasonable cross-section of patients subjected to cardiac surgery in Britain today. The survey reported here was designed against this background to give simple but accurate information about the postoperative course of our patients.

The fact that $68 \%$ denied limitation of normal activity 20 months after surgery, and that dyspnoea had been abolished in $62 \%$ after the same interval, reflects the improvement in physical well-being experienced by the majority of those under review. It is interesting that fear of exertion, a self-imposed limitation, increased immediately after discharge from hospital to become 
the major reason for limited activity at that stage. Even eight months after the operation this cautiousness was still apparent in $18(11 \%)$ patients but was eventually confined to three $(2 \%)$ one year later.

We cannot, therefore, confirm the conclusions drawn by O'Leary (1974), who found a reduced level of activity after aortic valve replacement compared with the preoperative level. The postoperative improvement in activity recorded during the present survey is reflected in the findings on employment. Twenty months after open-heart surgery $59(74 \%)$ men in this group were either back at work or, while registered as unemployed, regarded as 'capable of and available for gainful employment'. This represents an increase of $80 \%$ on the preoperative figure.

Seventy-six per cent of the male working population had returned to their usual jobs by 20 months after surgery. There was no correlation between the time taken to resume work and the patient's age or diagnosis.

The duration of postoperative sick leave among the nine patients aged 60 and over (Table 9) was comparable to that among younger patients. This supports the view that age of itself is not a contraindication to open-heart surgery.

The high proportion of unemployed men before operation (12\%) may be due in part to the current economic situation, but other factors may be responsible for a person being without work who is by definition 'capable of and available for gainful employment'. One such factor is the attitude of some employers to the stigma attached to heart disease. Another is that "work is a habit which, if allowed to lapse, is replaced by the habit of nonwork'. Blachly and Blachly (1968), who made this suggestion during a survey of 263 patients subjected to cardiac surgery, also formulated the 'law of the year', which states that 'if a person is unemployed for any reason for a period exceeding one year, the chance of re-employment is poor'. In the Wessex survey, five of the nine who were unemployed 20 months after surgery had been so for more than one year before operation.

Our results for return to work agree closely with those of Deiraniya (1976) at Harefield (NorthWest Thames Region), who studied the work pattern after homograft valve replacement in 70 individuals. In this restricted diagnostic category and with the review confined to those of preretirement age, he found that 51 of the 70 returned to their previous jobs, eight more resumed different full-time employment, and, of the remaining 11 , there were three who continued to work on a part-time basis. Thus $87 \%$ of the patients studied returned to full- or part-time employment.

The results in the Wessex series have shown the postoperative improvement in women's ability to undertake part- or full-time jobs as well as running their own homes. This is particularly gratifying, bearing in mind the longer period of preoperative disablement compared with men (Table 2). This difference between the sexes is related to the predominance of mitral valve disease among women.

The decreased dependence upon other members of the family, particularly among the older people under review, is another benefit from operation. Preoperative dependence was not determined solely by the patient's physical state. Some families become over-protective toward relatives with cardiac disease, so inhibiting the patient's selfreliance. After operation the family's rehabilitative role was repeatedly identified as an important one in helping the patient to return to work and share the household tasks. Here there has to be a balance between the help needed during the recovery of the patient's self-confidence and the counter-productive effect of an over-protective family.

Before operation the majority of patients reduced the amount of time spent on leisure activities as a result of increasing physical disability and lack of interest. During the postoperative period there was a revival of leisure activities, especially in more active pursuits such as gardening, home decorating, and swimming.

No attempt was made to assess changes of mood by psychometric testing, and our comments on this aspect of our patients' response to surgery are necessarily crude. We must record the often dramatic change in mental status that may follow cardiac surgery and which in this survey was shown by $56 \%$ of patients.

The mortality data quoted are for the total period of the survey and therefore represent the combined hospital and late deaths for the groups mentioned. An indication of the operative risk in the various categories into which our patients fell may be obtained from a recent review of our surgical results (Ross et al., 1976).

This survey shows an overall improvement in the quality of life for the majority of patients having open-heart surgery. In addition, the usefulness of many patients to their families or to the community is also enhanced. Although it is difficult to compare our results with those after treatment for other forms of chronic disabling disease, it is evident that they would stand such comparison. Some still regard cardiac surgery as a luxury item in the 
delivery of health care but the use of the word 'luxury' implies that there is a cheaper alternative. For these patients there is none.

This study was supported by the British Heart Foundation. We thank $\operatorname{Dr} A$. M. Johnson and Dr N. Conway, consultant cardiologists at the Wessex Cardio-Thoracic Centre, for their help and advice. We also thank the general practitioners and the consultants for allowing us to include their patients in this survey. To the patients who took part we are especially grateful.

\section{References}

Blachly, P. H., and Blachly, B. J. (1968). Vocational and emotional status of 263 patients after heart surgery. Circulation, 38, 524-532.

Cay, E. L., Vetter, N., Philip, A., and Dugard, P. (1972). Psychological status cluring recovery from an acute heart attack. Journal of Psychosomatic Research, 16, 425-435.

Cay, E. L., Vetter, N., Philip, A., and Dugard, P. (1973). Return to work after a heart attack. Journal of Psychosomatic Research, 17, 231-243.
Deiraniya, A. K. (1976). Return to work following valve surgery. Presented to the Society of Thoracic and Cardiovascular Surgeons of Great Britain and Ireland at the Annual Meeting, 23 September 1976.

Harris, R. (1970). Assessing the cardiac patient for rehabilitation. New York State Journal of Medicine, 70, 511-515.

Office of Population Censuses and Surveys (1970). Classification of Occupations, HMSO, London.

O'Leary, A. N. (1974). An assessment of patients' activity, knowledge and anxiety after prosthetic aortic valve replacement. M.Sc. Thesis, University of Toronto.

Rose, G., and Blackburn, H. (1968). Cardiovascular Survey Methods. World Health Organization, Geneva.

Ross, J. K., Monro, J. L., Manners, J. M., Edwards, J. C., Lewis, B., Hycle, I., Conway, N., and Johnson, A. M. (1976). Cardiac surgery in Wessex: review of 1,000 consecutive open-heart procedures. British Medical Journal, 2, 1485-1489.

Requests for reprints to: J. K. Ross, MS, FRCS, Wessex Cardiothoracic Centre, Western Hospital, Southampton SO9 4WQ, Hants, UK. 